\title{
AC 2010-960: A REVIEW OF PROGRAMMABLE LOGIC CONTROLLERS IN CONTROL SYSTEMS EDUCATION
}

\section{Michael Foster, George Fox University}

Michael Foster received a B.S. in engineering from Messiah College in 2002 and M.S. and Ph.D. degrees in mechanical engineering from Drexel University in 2006 and 2007, respectively. He is currently an Assistant Professor of Mechanical Engineering at George Fox University. His research interests include control systems education and thermal/fluid science applications.

\section{Chad Hammerquist, George Fox University}

Chad Hammerquist graduated from George Fox University in May 2010 with a B.S. in both engineering and mathematics. He is hoping to begin as doctoral candidate in mathematics this fall.

\section{Robert Melendy, George Fox University}




\title{
A Review of Programmable Logic Controllers in Control Systems Education
}

\begin{abstract}
A Programmable Logic Controller (PLC) is a standard industrial control device that provides a simple, yet robust, method of controlling manufacturing and dynamic processes. As a result of their low cost, adaptability, and reliability, PLCs are by far the most common control mechanism used by manufacturing businesses of all sizes for environment control, food processing, motion control, and automated test equipment. Yet even though PLCs are heavily used by industry, their use in teaching control theory concepts is uncommon for mechanical engineering programs. Traditional control systems engineering courses focus on the theory and mathematics of continuous-based control systems and rarely involve the use of PLCs, which provide an excellent platform to teach feedback control. Only a few programs have included a specific focus on non-continuous (on/off) control commonly used in industrial environments. In addition, learning ladder logic, a programming language for PLCs, can be difficult and seem unnecessary for those with a traditional programming background, such as $\mathrm{C}++$. Recognizing the appropriate ways of how and when to use PLCs is a key factor in applying control theory effectively in an industrial or even a research environment

This paper reviews the literature devoted to control systems education. It shows how academia is using PLCs in education and how it can complement the traditional focus on continuous-based control. A key objective of this paper is to review the PLC use in mechanical engineering education, which traditionally takes place in a control systems engineering course. This paper will also address a proposal by the authors that implementing PLCs into a control systems course for mechanical engineering students can enable a natural integration of continuous and non-continuous control theory.
\end{abstract}

\section{Introduction}

Engineering control problems can generally be categorized solely or as a combination of the following three ways: ${ }^{14}$

1. Continuous Linear - these systems can be described by linear differential equations, and exact equations can be used to design controllers.

2. Continuous Non-linear - these systems can be described with differential equations that are non-linear, and the controllers can be designed with some effort. In some systems differential equations are not available, forcing reliance on other methods, such as heuristic rules.

3. Non-continuous - these systems have discrete states and are characterized with on/off transitions of inputs and outputs. Logical decisions are required to control the system.

Control Systems Engineering is traditionally seen as a "dry" course by students with a mechanical concentration. The popular textbooks on the subject ${ }^{7,20,21}$ are meant for a more general engineering student audience, cover the theory that is typically associated with the subject, and 
focus mainly on continuous linear controls. Because of these areas of emphasis, reader motivation for the topic is difficult to maintain (a fact referenced in almost every book's introduction, followed by the authors' explanation of their approach to providing motivation). Over the years, these textbooks' approach to the subject has improved by adding more design problems and providing real-world examples. However, books can only provide mental exercises and/or suggest physical applications. Some engineering programs have gone a step further and chosen to include a laboratory experience along with the lecture. ${ }^{31}$ This approach enhances the in-class learning by providing hands-on applications.

In addition to focusing on continuous-based control systems, few engineering programs also include coverage of non-continuous (process or discrete) control that are common in industrial environments. Mechanical engineering graduates engage with both continuous and non-continuous control systems; however, they play a more key role in the development of non-continuous systems ${ }^{30}$ than continuous-based systems where additional education is usually required and/or their electrical engineering counterparts are better equipped. A valuable hands-on platform from which to teach both areas of control can be found in the process control industry - the programmable logic controller (PLC).

A few industrial, chemical, and electrical engineering as well as various technology programs have included some introduction to PLCs into their programs, where they are often presented as part of a laboratory course. However, several programs have begun offering courses dedicated to learning and applying PLCs. In contrast, very few mechanical engineering programs offer any exposure to PLCs throughout the curriculum. ${ }^{14,25}$ Yet, they remain the most common and useful component in controlling manufacturing processes and machinery. Mechanical engineers need to understand how issues of control can affect their designs of new machines and operator interfaces. Unfortunately, many engineers lack knowledge in areas of cross-discipline knowledge. They become specialized in their own field to the fault of not considering (or even knowing) how their role in a project impacts the other participants. ${ }^{17}$ If students can gain a strong understanding of how to apply control theory in real-world applications, they will diversify their knowledge set and can communicate and design more effectively. Additional arguments have been made for including PLCs in controls education. ${ }^{13,14,18}$

\section{Background}

This section highlights the history and context for the PLC and the motivation for pursuing this investigation.

\section{History}

PLCs were first developed by Information Instruments, Inc. (acquired by Allen-Bradley in 1969) for the Hydra-matic Division of General Motors in $1968^{2}$ to reduce the turnaround time when new production lines were implemented. The compact physical structure of PLCs significantly reduced the space taken by previous physical components (relays, timers, etc.). Instead of building a large mechanical setup of components to control a process, the same "components" could be dragged-and-dropped in a computer interface, saving setup cost and time as well as long-term maintenance. 
The software language created for PLCs, called "ladder logic," retained a very similar look to the wiring diagrams that were used for the physical components it replaced. This software design was intentional as it enabled technicians to quickly understand and update the logic as changes were needed with minimal additional training. In addition, ladder logic (and other PLC-based programming languages) offer a graphical real-time visualization of program and machine operation, unlike most compiled languages, which aids in system troubleshooting. As a result, control engineers have a platform that is easy to read, easy for maintenance technicians to troubleshoot, and usually allows runtime modifications, all with higher reliability than the mechanical analogs.

This review will focus on the use of ladder logic, which is generally acknowledged as the most dominant programming language for non-continuous/discrete control. However, most of todays high end PLCs support the "IEC-1131" specification, which describes several different programming languages: ${ }^{18}$

1. Ladder Logic - primarily for non-continuous discrete control.

2. Function Block - primarily for process and loop control (the standard language of the traditional Distributed Control System).

3. Structured Text-a text based language that allows more sophisticated constructs not easily duplicated in ladder or function block languages.

4. Sequential Function Block - a graphical step based structure for organizing blocks of code written in one of the other languages.

5. Statement List—-similar to Structured Text.

With the increased flexibility of the PLC with multiple languages and the ability to handle all forms of discrete, process, and motion control (including PID control), manufacturers are increasingly referring to their top of the line products as "PACs" (Programmable Automation Controllers) to differentiate them from older generation ladder logic only controllers.

Furthermore, "online" programming has become the single most important feature of most high value control systems. ${ }^{18}$ This feature is something that few "compiled" languages (such as C++ or Visual Basic) can offer.

It is clear that today's PLC (or PAC) is seen by industry as far more than a simple ladder logic engine.

\section{Motivation}

The authors initiated this review as a result of the many changes the Control Systems Engineering course at George Fox University has undergone in the brief history of the engineering program. An electrical engineering professor taught the original version of the course, which was a requirement for both concentrations (mechanical and electrical). The laboratory experience changed from controlling a robot around a course using MATLAB ${ }^{\mathrm{TM}}$ to a computer control simulation. The professor was not pleased with the results or the direction of the projects. Subsequent departmental discussions led to the development of a controls course for juniors only in the mechanical concentration track. 
With the shift to a mechanical engineering focus, five Allen-Bradley PLCs were purchased to enable a hands-on laboratory experience through applying control theory concepts. During the first offering of the mechanical-focused course, students developed PLC projects on paper but they were not implemented due to the limited availability of supporting hardware. Setup difficulties, due to attempts at connecting CPUs to PLCs via the campus intranet, limited PLC implementation until the communication issue was resolved by connecting each PLC directly with a dedicated CPU. During the Spring 2009 session, students were introduced to ladder logic programming through a parking garage ticketing example. ${ }^{1}$ During the subsequent laboratory sessions, they completed a breadboard prototype and ladder logic program for the traffic signaling of a local intersection.

Student feedback on this single project was very positive. They valued the practically of the experience and would have enjoyed more time to learn and practice ladder logic. In general, students were familiar with structured programming from previous courses, so grasping ladder logic came as a new experience.

At present, the engineering program curriculum has undergone another (minor) shift due to the addition of a required course sequence in Servant Engineering. ${ }^{12}$ The Control Systems Engineering course will now be taught to mechanical engineering seniors in the fall semester. Thus, the timing was appropriate to review the approaches to controls education, specifically as they relate to mechanical engineering.

\section{Literature}

A natural division of the reviewed literature was made between PLC implementation in control system courses and ways of teaching ladder logic. These areas are presented separately in the following section.

\section{PLC Implementation}

Reviewing the educational literature for descriptions of PLC projects (see Table 1), it was rare to find papers where all authors were from a mechanical engineering department. ${ }^{25}$ The remaining articles include or are solely written by individuals from electrical/computer engineering or engineering technology departments. The lack of PLC projects indicates that very few programs are taking advantage of a versatile tool, where as papers involving collaborative inter-departmental efforts demonstrate the willingness or need to capitalize on commonalities between disciplines. ${ }^{29}$

The collaborations also highlight the robust feature set that PLCs have gained since their replacement of cumbersome electro-mechanical systems 40 years ago. The projects listed in Table 1 indicate a variety of non-continuous and continuous-based control implementation. In particular, one laboratory contains an array of experiments with electrical, mechanical, pneumatic, and hydraulic systems. ${ }^{11}$ Another program provides a thermal process control lab. ${ }^{4}$ Note that very similar projects are offered from both mechanical and electrical engineering departments, yet the outcome of each project is appropriate to the area. For example, students in both areas of engineering investigate the control of DC motors ${ }^{6,25}$ and conveyors ${ }^{5,26}$. 
Table 1: PLC projects from the literature with the area(s) of engineering in which the course is offered, the project, and the equipment necessary (other than a PLC and a computer).

\begin{tabular}{|c|c|c|}
\hline $\operatorname{Area}(s)^{\dagger}$ & Project(s) & Equipment \\
\hline$E^{28}$ & Controlling a stepper motor & Driver board, stepper motor \\
\hline $\mathrm{E}^{19}$ & $\begin{array}{l}\text { Automatic control of laundry wash- } \\
\text { ing machine }\end{array}$ & $\begin{array}{l}\text { Rockwell's WinView (provides a virtual environ- } \\
\text { ment) }\end{array}$ \\
\hline $\mathrm{ET}^{22}$ & $\begin{array}{l}\text { 1. Control of filling a tank } \\
\text { 2. Hybrid boat control system } \\
\text { 3. Control of a movable conveyor } \\
\text { for a trailer }\end{array}$ & $\begin{array}{l}\text { 1. Tank with sensors } \\
\text { 2. Various motor and photovoltaic components } \\
\text { 3. Conveyor and sensors }\end{array}$ \\
\hline \multirow[t]{3}{*}{$E^{6}$} & $\begin{array}{l}\text { 1. Full-step stepper motor controller } \\
\text { 2. Half-stepping stepper motor con- } \\
\text { troller }\end{array}$ & $\begin{array}{l}\text { 1. Stepper motor, solid-state isolated relays } \\
\text { 2. Stepper motor, solid-state isolated relays }\end{array}$ \\
\hline & $\begin{array}{l}\text { 3. Lead screw/limit switch control } \\
\text { device }\end{array}$ & $\begin{array}{l}\text { 3. DC motor-driven lead screw, small block, limit } \\
\text { switch }\end{array}$ \\
\hline & $\begin{array}{l}\text { 4. Closed-loop heating/cooling tem- } \\
\text { perature control system }\end{array}$ & $\begin{array}{l}\text { 4. Water-filled metal cylinder, RTD sensor, voltage- } \\
\text { controlled heating element, and a small computer fan }\end{array}$ \\
\hline \multirow[t]{2}{*}{$E^{26}$} & 1. Physical security system & $\begin{array}{l}\text { 1. Motion detector, magnetic contact, vibration de- } \\
\text { tector, panic button, switches, light stack }\end{array}$ \\
\hline & 2. Conveyor system control & $\begin{array}{l}\text { 2. Switches, light stack, a second PLC, powered } \\
\text { rollers, infrared sensors }\end{array}$ \\
\hline \multirow{2}{*}{$\mathrm{M}, \mathrm{E}^{10}$} & 1. Light stack experiment & 1. Switches, lamps \\
\hline & 2. Conveyor belt experiment & $\begin{array}{l}\text { 2. Proximity sensor, pneumatic cylinder, powered } \\
\text { conveyor belt system, light stack }\end{array}$ \\
\hline $\mathrm{T}^{8}$ & Automated labeling system & $\begin{array}{l}\text { Powered conveyor belt, labeling machine, solenoid } \\
\text { valve, double acting pneumatic actuator, photoelec- } \\
\text { tric sensor, relays, two DC power supplies, and a stor- } \\
\text { age area for packaging the parts }\end{array}$ \\
\hline \multirow{4}{*}{$\mathrm{M}^{25}$} & 1. Traffic light control & 1. Switches, LEDs \\
\hline & 2. Thermometer & 2. Thermocouple, display \\
\hline & 3. Battery tester & $\begin{array}{l}\text { 3. NI-CAD batteries, dry cell } 1.5 \text {-volt batteries, and } \\
\text { dry cell 9-volt batteries, display, LEDs }\end{array}$ \\
\hline & 4. Control a DC motor & 4. DC motor, strobe-a-tach \\
\hline \multirow{3}{*}{$M^{5}$} & 1. Traffic light sequence & 1. Light stack \\
\hline & 2. Traditional conveyor experiment & 2. Conveyor, integrated actuators, sensors, pallet \\
\hline & 3. Smart conveyor system & $\begin{array}{l}\text { 3. MicroRollers, idler rollers, light stack, sensors, } \\
\text { robotic arm integration }\end{array}$ \\
\hline $\mathrm{EmT}^{23}$ & Flow control trainer & $\begin{array}{l}\text { Centrifugal blower, clear plastic tubing, flow sensor, } \\
\text { damper valve, switches }\end{array}$ \\
\hline $\mathrm{MT}^{4}$ & Thermal process control & $\begin{array}{l}\text { Thermocouple, thermocouple module for PLC, car- } \\
\text { tridge heater, relay }\end{array}$ \\
\hline $\mathrm{MT}^{3}$ & Three-phase motor control & $\begin{array}{l}\text { Motor, fuses, transformer, buttons, LEDs, relays, mo- } \\
\text { tor starter, misc. parts }\end{array}$ \\
\hline
\end{tabular}

${ }^{\dagger} \mathrm{E}=$ Electrical/Computer Engr., $\mathrm{M}=$ Mechanical Engr., Em = Electro-mechanical Engr., $\mathrm{T}$ = Technology 
Along with descriptions of the specific projects, different ways of implementing PLCs into the curriculum are outlined. Ohio Northern University's mechanical engineering department teaches a required classical control systems course in the winter quarter and offers an elective course in PLCs the following term. ${ }^{25}$ At Grand Valley State University, the Dynamic Systems Modeling and Control course was revised to eliminate Laplace transforms allowing more instructional focus on mechanical engineering appropriate methods of problem solving. ${ }^{15}$ In addition, their Manufacturing Control Systems course (which follows the previously mentioned Dynamic Systems course) provides additional logic-based control instruction with different aspects of PLCs practiced in the laboratory section throughout the term. ${ }^{14}$ An open source book has also been produced for the course. ${ }^{17}$ For control system courses that feature more mechanical engineering focused content, detailed sequences of topics (for both lecture and laboratory) are available. ${ }^{16,31}$

The integration of PLC-based control systems and the Ethernet-based business and information networks in industrial environments has become one of the most important areas of development in recent years. Detailed knowledge of Ethernet and TCP/IP technology is not wide spread yet, as most control engineers know the basics but few understand how to design an optimized high performance information layer on top of a control system. This communication feature of the PLC is being exploited through an internet-based remote control automation laboratory, which provides additional skills for engineering students. ${ }^{9}$ An additional internet-based resource that is being developed is a Virtual PLC_— “a system that integrates multiple instructional technologies and techniques into a single Web-based learning system that is comprehensive in its treatment of PLC topics, motivational, and always available." 13

\section{Teaching Ladder Logic}

From the authors' experiences and the examples given by colleagues in teaching ladder logic programming, students struggle with how to structure a ladder diagram from a given problem statement. Specific approaches have been offered in the literature as ways to acquire effective programming skills.

James Rehg describes two approaches to ladder logic programming: empirical and pseudo structured. ${ }^{24}$ Noting that the empirical approach is well suited for small applications, he details a pseudo structured approach, called sequential function charts. This process requires extended planning and development time of the programming but significantly reduces the implementation and troubleshooting of programming problems.

Another approach to ladder logic programming is "I/O mapping," developed by Durward Sobek at Montana State University. ${ }^{27}$ At the start of the design sequence, each system input and output are listed or diagrammed separately on a page. Links are then drawn from the inputs to any output they effect. Finally, a Boolean expression is developed for each output, which enables an easier translation into programming rungs. The author presents some quantitative data indicating that both quality and efficiency in the problem solving process improved. 


\section{Discussion}

There is an evident need for a more holistic approach to control system education for undergraduate mechanical engineering students. This course would still include much of the traditional, continuous control coverage, yet also introduce non-continuous control system techniques and approaches. In addition, a key area of need is the presentation of the PLC platform, from which all areas of control can implemented. To achieve this end, more formal educational resources that provide a clear and full presentation of control systems engineering for the mechanical engineering student are necessary. This shift in control education philosophy cannot happen without the support of administrations and adoption by departments of curriculum that provides a complete coverage of the control engineering field.

Recently, a conversation with an alumnus led to discussion about the current singular focus that mechanical engineering control system education has on continuous control versus a holistic approach. The alumnus's undergraduate degree was in engineering with a mechanical concentration; he worked for three years as a controls engineer on multiple projects requiring the use of PLCs. He pointed to his work experience as a key factor for his current pursuit of a Ph.D. in electrical engineering and feels that exposure to PLCs and ladder logic programming would have been very helpful in his initial job search and work experience. ${ }^{30}$ While LabVIEW ${ }^{\mathrm{TM}}$ and MATLAB $^{\mathrm{TM}}$ are very popular in control engineering labs, the knowledge of how to apply PLCs to a given application has substantial relevance to the mechanical engineering student's education and future professional journey.

Non-technical factors, that have not yet been mentioned, also contribute to the PLC's value: ${ }^{18}$ (a) local availably of parts, (b) large installed base, (c) easy for non-engineer technicians to interface with, (d) understood by a large number of licensed electricians, and (e) very robust and durable components. The PLC's ability to execute both non-continuous and continuous control functions and its ubiquitous usage in industry make it a valuable tool in engineering education.

\section{Conclusions}

Implementing PLCs into a control systems course for mechanical engineering students can enable a natural integration of continuous and non-continuous control theory. The presentation of the industrial and academic background of PLC development and use has demonstrated the PLC's value and versatility. Arguments made challenge the current structure of most control system engineering courses for their sole continuous-based systems focus and encourage the increased exposure of students to the PLC. As an industry-wide tool with functionality for non-continuous and continuous systems, it will enhance the value of controls education by allowing a more holistic approach.

\section{Acknowledgments}

This project was supported in part by George Fox University Grant GFU09G0006. 


\section{Bibliography}

1. Allen-Bradley. Micromentor: Understanding and applying micro programmable controllers. Publication 1761-MMB, 1995.

2. Allen-Bradley. Success isn't so much a product of technology, as it is a product of listening, Retrieved January 2, 2010, from http://www.rockwellautomation.com/ab100years/pdf/1995_ PLC_ 25_ Years.pdf, 1995.

3. ANDERSON, J. C. Designing a flexible industrial controls lab module. 32th ASEE/IEEE Frontiers in Education Conference (2002).

4. ANDERSON, J. C. A thermal process control laboratory. 34th ASEE/IEEE Frontiers in Education Conference (2004).

5. Bassily, H., Sekhon, R., Butts, D. E., And Wagner, J. A mechatronics educational laboratory-programmable logic controllers and material handling experiments. Mechatronics 17 (2007), $480-488$.

6. CAVICCHI, T. Integration of programmable logic controller programming experience into control systems courses. Proceedings of the 2008 ASEE Annual Conference \& Exposition (2008).

7. Dorf, R. C., AND Bishop, R. H. Modern Control Systems. Prentice Hall, Upper Saddle River, NJ, 2008.

8. Eslami, A., OXEndine, A., AND DANiels, C. A PLC project in a control course laboratory. Proceedings of the 2008 ASEE Annual Conference \& Exposition (2008).

9. Eslami, A., Williams, A., AND Krauss, K. A remote-access robotics and PLC laboratory for distance learning program. Proceedings of the 2009 ASEE Annual Conference \& Exposition (2009).

10. Ghone, M., Schubert, M., AND WAGner, J. R. Development of a mechatronics laboratory-eliminating barriers to manufacturing instrumentation and control. IEEE Transactions on Industrial Electronics 50, 2 (2003).

11. Ghone, M., And Wagner, J. A multi-disciplinary mechatronics laboratory. Proceedings of the 2003 ASEE Annual Conference \& Exposition (2003).

12. Grose, T. K. Service engineering: Not an option. ASEE Prism 19, 3 (November 2009), 16.

13. Hsieh, S., AND Hoermann, K. An integrated virtual-learning system for a programmable logic controller (virtual PLC): Current progress and future directions. Proceedings of the 2009 ASEE Annual Conference \& Exposition (2009).

14. JACK, H. Teaching controls with PLCs. Proceedings of the 2000 ASEE Annual Conference \& Exposition (2000).

15. JACK, H. System modeling and control for mechanical engineers. Proceedings of the 2002 ASEE Annual Conference \& Exposition (2002).

16. JACK, H. Teaching mechanical students to build and analyze motor controllers. Proceedings of the 2003 ASEE Annual Conference \& Exposition (2003).

17. JACK, H. Automating Manufacturing Control Systems; with PLCs, Retrieved January 2, 2010, from http://engineeronadisk.com/book_ plcs, 2008.

18. Macdougall, B. Personal interview. January 7, 2010.

19. Martin, T. PLC's in the control system laboratory. Proceedings of the 1999 ASEE Annual Conference \& Exposition (1999).

20. NiSE, N. Control Systems Engineering. Wiley, Hoboken, NJ, 2008.

21. Ogata, K. Modern Control Engineering. Prentice Hall, Upper Saddle River, NJ, 2002.

22. PeCEn, R., AND Guo, L. Design projects in a programmable logic controller (PLC) course in electrical engineering technology. Proceedings of the 2008 ASEE Annual Conference \& Exposition (2008).

23. REHG, J. A. Design of a low cost trainer for flow control. 28th ASEE/IEEE Frontiers in Education Conference (1998).

24. ReHG, J. A. Structured PLC programming with sequential function charts. Proceedings of the 2001 ASEE Annual Conference \& Exposition (2001).

25. Rider, M. A unique, undergraduate PLC course. Proceedings of the 2004 ASEE Annual Conference \& Exposition (2004).

26. Shirley, T., Wagner, J., Collins, R., And Anand, G. A mechatronics (and material handling systems) course-classroom topics, laboratory experiments, and project. Proceedings of the 2009 ASEE Annual Conference \& Exposition (2009).

27. SobeK, D. K. Teaching novices how to program PLC's. Proceedings of the 2001 ASEE Annual Conference \& Exposition (2001).

28. SoKoloff, L. PLC stepper motor controller. Proceedings of the 1998 ASEE Annual Conference \& Exposition 
(1998).

29. Spong, M. W. Control education crossing department boundaries. Proceedings of the American Control Conference (1999).

30. Stillinger, C. Personal interview. August 6, 2009.

31. Yoder, J., Hurtig, J., And Rider, M. Providing hands-on experiences in a mechanical engineering controls systems course. Proceedings of the 2004 ASEE Annual Conference \& Exposition (2004). 